\title{
Luminescence dating of architectural ceramics from an early medieval abbey: The St Philbert Intercomparison (Loire Atlantique, France)
}

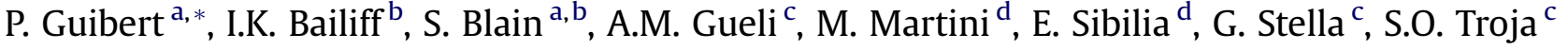 \\ ${ }^{a}$ CNRS-Universite Bordeaux, UMR 5060, IRAMAT-CRP2A, Maison de l'Archéologie, F-33607 Pessac, France \\ ${ }^{\mathrm{b}}$ University of Durham, Department of Archaeology, Luminescence Laboratory, South Road, Durham, DH1 3LE, UK \\ ${ }^{c}$ LDLEBBCC, Department of Physics and Astronomy, Centro Siciliano di Fisica Nucleare e di Struttura della Materia, Università di Catania E INFN Sezione di Catania, \\ via Santa Sofia 64, I-95123 Catania, Italy \\ 'INFN, CNR-INFN and CUDAM, Univ. Milano Bicocca, U5, via R. Cozzi 53, I-20125 Milano, Italy
}

\section{A R T I C L E I N F O}

\section{Article history:}

Received 20 October 2008

Received in revised form

19 March 2009

Accepted 11 June 2009

\section{Keywords:}

Luminescence dating (OSL and TL)

Quartz inclusion technique

Polymineral fine grain technique

Brick

Early medieval

\begin{abstract}
A B S T R A C T
An experimental intercomparison was performed with brick samples from an early medieval building in the west of France, the St-Philbert-de-Grandlieu abbey. A potentially complex set of microdosimetric problems emerged from characterisation measurements, providing a robust test of the routine procedures used by each laboratory. The dating results obtained using quartz coarse grains and fine grain samples span over a large period of time, exhibiting overdispersion, and where systematic deviations appear between quartz and fine grain chronologies. Factors causing such scatter are analysed in detail, including internal radioactivity of quartz grains, millimetre-scale heterogeneity in the fabric, and the observation and modelling of fading behaviour of fine grain minerals.
\end{abstract}

(c) 2009 Elsevier Ltd. All rights reserved.

\section{Introduction}

An international intercomparison experiment of luminescence dating of medieval bricks was performed under the auspices of the CNRS within the framework of a European research group. This network called 'architectural ceramics and dating methods' is a multidisciplinary team composed of building archaeologists, historians of medieval art and dating specialists (radiocarbon, archaeomagnetism and luminescence). The principal archaeological aims of the group are to study the production or the re-use of bricks in early medieval construction, and in the former case, to obtain new chronological data. The primary methodological aim of the study was to improve the application of luminescence dating techniques and to test the capability of routine procedures with heterogeneous ceramics samples obtained from a particular building, the abbey of St-Philbert-de-Grandlieu.

\section{Site, history and sampling}

The abbey of St-Philbert-de-Grandlieu belongs to a key series of early medieval monuments of the Carolingian period, the

\footnotetext{
* Corresponding author. Tel.: +33 557124549; fax: +33 557124550.

E-mail address: guibert@u-bordeaux3.fr (P. Guibert).
}

chronology of which is the subject of this investigation. The majority of the monuments are situated in the north-west of France, and St Philbert was selected following the successful outcome of a chronological study of the church Notre-Dame-sousTerre at the Mont-Saint-Michel (France) (Blain et al., 2007). The abbey is located $40 \mathrm{~km}$ south-west of Nantes (Loire Atlantique, France), set in the geological context of the Armorican Massif which forms part of the primary Hercynian Massif. It was built near marshland on a small mound of schist that would have been exploited for its construction materials (Lebouteux, 1965; Lasteyrie, 1911). The existence of a primitive church, that was later to become the abbey, is mentioned in documents of the early IXth century AD. Historical records suggest that the monument was abandoned during Norman incursions in the mid IXth century, but that monks reoccupied and restored the church at the turn of the first millennium (all dates referred to in this paper are AD).

Eight samples of brick from the south and east arches of the transept were sampled for combined luminescence dating and archaeomagnetic studies using a water lubricated core drill (20$25 \mathrm{~cm}$ in length and $35 \mathrm{~mm}$ diameter). Four bricks were also sampled in the north east part of the choir. According to archaeological structural analysis (unpublished data), both arches sampled belong to the same phase of construction, with similar brick dimensions and pattern and mortar. They are connected to the structure of the early church, the construction of which is 
attributed to the beginning of the IXth century by historical records. Radiocarbon dates obtained for charcoal fragments extracted from the mortars used in the earliest walls of the church place the construction during the VIIIth and Xth centuries AD (at 95\% level of confidence) and these data are considered as a reference chronology for the luminescence dating experiment described in this work (Table S1).

Four samples taken from the arches (denoted STPG-1, $-2,-8$ and -10) were selected for the intercomparison and divided into four parts, one part having been given to each luminescence laboratory (denoted BDX, Bordeaux; CAT, Catane; DUR, Durham; MIL, Milan). Dosimeter capsules (containing $\mathrm{CaSO}_{4}$ :Tm) were placed inside the remaining holes for combined gamma and cosmic dose rate measurement, and activity measurements were performed at these locations using a portable gamma ray spectrometer ( $\mathrm{NaI}: \mathrm{Tl})$ to estimate the cosmic dose rate. The capsule dose rate was evaluated by Bordeaux and the gamma dose rate profile in the bricks was calculated by Catane on the basis of experimental measurements performed on 2 intercomparison bricks ( 3 capsules were set in STPG-1 and -2). All other measurements and determinations of ages were conducted independently by each laboratory and communicated at the first meeting, one year after sampling (at this stage the radiocarbon results were not known).

\section{Characterisation of the ceramics}

The fabrics of the brick samples were very coarse, comprising a clay matrix with a high proportion of sand temper containing grains extending to several millimetres in size. A series of characterisation experiments were performed at Bordeaux following distribution of the core samples. Optical petrography of thin sections revealed the presence of aggregates of quartzite, more or less altered and fragile, and other rock fragments including granite and schist. Cathodoluminescence measurements with cut and polished sections revealed many K-feldspars (light blue luminescence), some of which were contained in large quartz grains (Fig. 1). In addition, some grains within the size range of interest in routine dating measurements $(100-300 \mu \mathrm{m}$ diameter) were found to contain small zircons $(20-30 \mu \mathrm{m}$ diameter $)$, and in one case

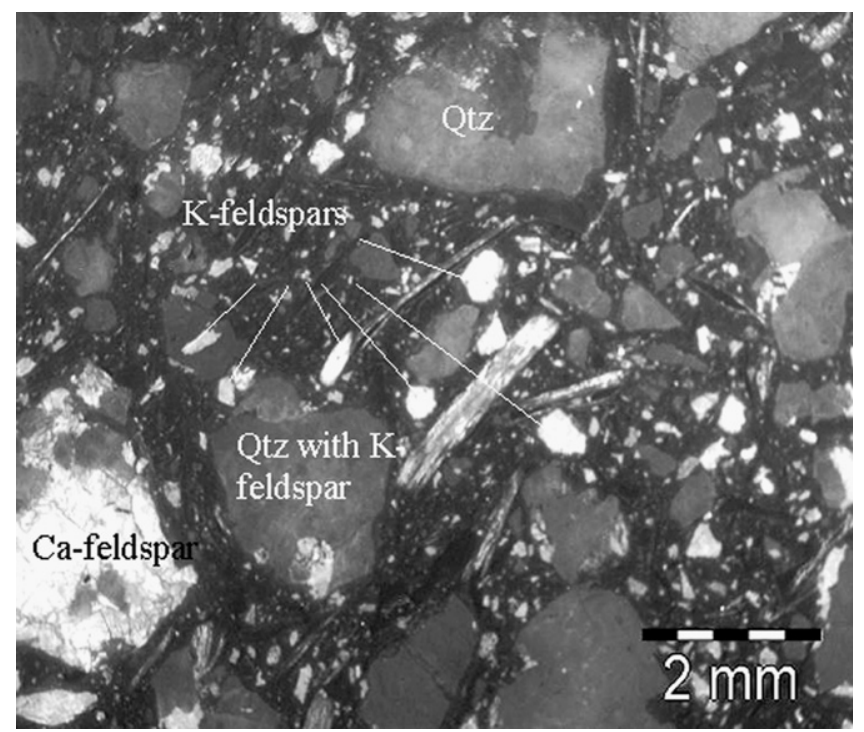

Fig. 1. Cathodoluminescence of a thin section of Bdx10222, one of the bricks sampled at the south arch, showing a high concentration of coarse grains (light spots are mainly $\mathrm{K}$-feldspars, dark grey crystals are quartz, large quartz grains contain feldspar inclusions) (photo IRAMAT-CRP2A). a monazite inclusion was detected (Fig. 2). The observed proportion of this type of quartz by thin section analysis was $4 \%$ ( 16 out of 430 grains: 6/121 in Bdx10226 STPG-8, 5/127 in Bdx10223, 5/182 in Bdx10224), indicating that the proportion of quartz grains with internal high radionuclide concentrations of this type could be as high as $20 \%$ (by translating from surface to volumetric proportions). Hence these ceramics were of distinctly heterogeneous composition. Also, on the basis of inspection using optical microscopy of the surfaces of cut slices of core and aliquots of crushed material, the Durham laboratory assessed their core sections of STPG-2, -8 and -10 to contain a high proportion of coarse quartz grains that fragmented on crushing.

\section{Methods}

Although a potentially complex set of microdosimetric problems was emerging from the initial characterisation discussed above, it was decided to continue the intercomparison to test the extent of robustness of the routine procedures as used by each laboratory for dating bricks. The quartz inclusion and fine grain techniques were applied. Using these two techniques the major experimental issues for the St Philbert samples were spatial variation of beta dose rate (quartz inclusion) and anomalous fading (fine grain, where reliant on feldspar emission).

\subsection{Paleodose: quartz inclusion technique}

Table 1 contains a summary of the procedures followed by each laboratory, including the preparation details.

\subsubsection{Bordeaux}

TL measurements were performed with the $80-200 \mu \mathrm{m}$ fraction of sieved and treated coarse grains using the additive dose and regeneration TL technique. The procedure includes a sensitivity recovery test (Roque et al., 2004) to determine appropriate annealing conditions, depending on the particular characteristics of the sample. An $\mathrm{H}_{2} \mathrm{SiF}_{6}$ etching procedure (Blain et al., 2007) was applied to remove feldspars and other silicate minerals and to avoid the anisotropic effects of conventional high concentration HF etching of quartz (hence the paleodose measured included the

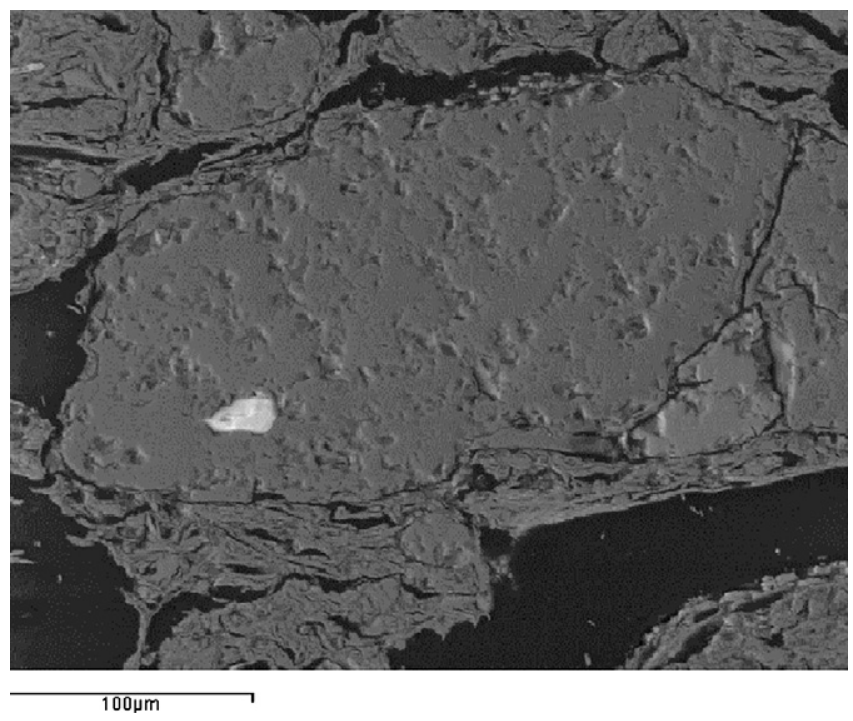

Fig. 2. BSE-SEM image by atomic number contrast showing a zircon inclusion inside a quartz grain.(STPG-8, Bdx10226) (photo IRAMAT-CRP2A). 
Table 1

Instrumental details and methods for paleodose determination with quartz grains (Blain et al., 2007; Bailiff, 2007).

\begin{tabular}{|c|c|c|c|c|c|}
\hline Lab & Sample preparation & Etching control & Method and protocol & $\begin{array}{l}\text { Zeroing process before } \\
\text { regeneration }\end{array}$ & Instrumental parameters \\
\hline DUR & $\begin{array}{l}90-150 \mu \mathrm{m} ; \mathrm{HCl}(1 \mathrm{M}), 40 \% \mathrm{w} \mathrm{HF} \\
\text { etch } 40 \mathrm{~min} \text { at room temperature } \\
(\mathrm{RT})\end{array}$ & $\begin{array}{l}\text { IRSL test and } \\
\text { microscope } \\
\text { examination }\end{array}$ & $\begin{array}{l}\text { OSL single aliquot regenerative } \\
\text { and additive techniques }\end{array}$ & Optical & $\begin{array}{l}\text { Preheat: } 200-240{ }^{\circ} \mathrm{C}, 10 \mathrm{~s} \text { hold; OSL } \\
\text { measured at } 125^{\circ} \mathrm{C} \text {. Detect: Schott } \\
\text { UG-11; Risø reader }\end{array}$ \\
\hline BDX & $\begin{array}{l}80-200 \mu \mathrm{m}, \mathrm{HCl}(1 \mathrm{M}), 31 \% \mathrm{w} \mathrm{H}_{2} \mathrm{SiF}_{6} \\
\text { for } 6-15 \text { days at RT (acid renewed } \\
\text { every } 3 \text { day interval), densimetric } \\
\text { selection }(\rho>2.67 \mathrm{~g} / \mathrm{cm} \text { and } \\
\rho<2.62 \mathrm{~g} / \mathrm{cm} \text { rejected })\end{array}$ & CL inspection & $\begin{array}{l}\text { Multiple aliquot TL additive } \\
\text { dose and regenerative } \\
\text { technique; a-value } \\
\text { measurements on annealed } \\
\text { crushed quartz }\end{array}$ & $\begin{array}{l}\text { Annealing in air for } 1 \mathrm{~h} \text { at } 550 \text {, } \\
600,650 \text { and } 650^{\circ} \mathrm{C} \text {, for } \\
\text { samples } 1,2,8 \text { and } 10 \\
\text { respectively }\end{array}$ & $\begin{array}{l}\text { Preheat: } 120 \mathrm{~s} \text { at } 190{ }^{\circ} \mathrm{C} ; 4{ }^{\circ} \mathrm{C} / \mathrm{s} \text {. Detect: } \\
\text { 2, Schott BG12 and } 1 \mathrm{IR} \text { rejection MTO } \\
\text { Ta3, PM EMI } 9813 \mathrm{KA} \text {; Lab designed } \\
\text { TL-reader. TL ROI: } 300-450{ }^{\circ} \mathrm{C}\end{array}$ \\
\hline CAT & $\begin{array}{l}100-300 \mu \mathrm{m}, \mathrm{HCl}(2.5 \mathrm{M}), 40 \% \mathrm{w} \mathrm{HF} \\
\text { for } 40 \mathrm{~min} \text { at RT, densimetric } \\
\text { selection }\end{array}$ & $\begin{array}{l}\text { Microscope } \\
\text { examination }\end{array}$ & $\begin{array}{l}\text { TL SAR-like technique as } \\
\text { a methodological test (Bassinet } \\
\text { et al., 2006) }\end{array}$ & 2 successive cut heat at $500^{\circ} \mathrm{C}$ & $\begin{array}{l}\text { Preheat } 15 \mathrm{~s} @ 290{ }^{\circ} \mathrm{C} \text {; heating rate } 5{ }^{\circ} \mathrm{C} / \\
\text { s; Detect: Corning } 7-59 \text { \& Schott UG- } 11 \\
\text { \& BG-39; PMT EMI 9235QA; Risoe } \\
\text { TL/OSL reader; TL ROI: } 300-450{ }^{\circ} \mathrm{C}\end{array}$ \\
\hline
\end{tabular}

alpha dose contribution to the outer layers). The alpha efficiency of the quartz was measured using crushed and powdered quartz grains from the initial $80-200 \mu \mathrm{m}$ preparation that were annealed and then separated (3-12 $\mu \mathrm{m})$ by sedimentation. For the purposes of these experiments we have assumed that the alpha efficiency of the homogenised quartz is a reasonable approximation of the subsurface (external alpha dose) and inner quartz (internal grain alpha dose).

\subsubsection{Durham}

A single aliquot regeneration (SAR) OSL procedure was applied to aliquots of $90-150 \mu \mathrm{m}$ HF etched quartz coarse grains that has been developed for brick samples (Bailiff and Holland, 2000; Bailiff, 2007), and an additive dose SAR procedure was also employed to check for changes in luminescence characteristics during the first laboratory measurement. Following a SAR procedure, the value of the paleodose was determined for several preheat temperatures in the interval $200-240{ }^{\circ} \mathrm{C}$. The alpha efficiency of crushed HF etched quartz was also measured.

\subsubsection{Catane}

A single aliquot TL procedure was applied with 100-300 $\mu \mathrm{m} \mathrm{HF}$ etched quartz grains (Mejdahl, 1985; Godfrey-Smith et al., 1988, Aitken, 1998). To check the grain sizes of separate fractions, observations were made by using scanning electron microscope (SEM) and the purity of the fractions was checked by X-ray diffraction. Estimates of paleodose were obtained using a SAR protocol (Bassinet et al. 2006).

\subsection{Paleodose: fine grain samples}

Table 2 contains a summary of the fine grain preparation procedures followed by each laboratory and details of the luminescence measurement procedures. The sample preparation procedures used by BDX, CAT and MIL are based on the conventional fine grain technique described by Aitken (1985). The primary differences in preparation lie in the application of etching treatments of differing aggressiveness, ranging from the lightest by Milan to the heaviest by Bordeaux. Etching of fine grains with $\mathrm{H}_{2} \mathrm{SiF}_{6}$ by Bordeaux to isolate quartz was unsuccessful since the concentration of quartz produced was insufficient.

The protocols for paleodose determination also differed, the key differences being highlighted here. The annealing procedure prior to measurement of the regenerative growth curve applied by Bordeaux (as for coarse quartz grains discussed above) avoids the need to apply a supralinearity correction associated with the conventional fine grain procedure, whereas both Milan and Catane obtained by extrapolation a (small) supralinearity correction using aliquots that were sensitised after an annealing treatment comprising two cut heats to $500{ }^{\circ} \mathrm{C}$. The extent of the signal plateaux region employed for paleodose evaluations by Catane and Milan was relatively narrow $\left(\sim 50^{\circ} \mathrm{C}\right)$ compared with that $\left(180^{\circ} \mathrm{C}\right)$ used by Bordeaux.

\subsection{Annual dose assessment}

Apart from the common measurement (by Bordeaux) of the combined gamma and cosmic dose rate at the sampling locations

Table 2

Instrumental details and methods for paleodose determination with fine grains (Guibert et al., 1998; Gallo et al., 1999; Gueli et al., 2001).

\begin{tabular}{|c|c|c|c|c|c|c|}
\hline Lab & Sample preparation & Method and protocol & $\begin{array}{l}\text { Zeroing process before } \\
\text { regeneration }\end{array}$ & Plateau & Fading meas. & Instrumental parameters \\
\hline$\overline{\mathrm{BDX}}$ & $\begin{array}{l}\mathrm{HCl}(1 \mathrm{M}) \text { for } 100 \mathrm{~min} \text { at } \mathrm{RT} \\
\text { on } \emptyset<40 \mu \mathrm{m} \text { grains, } \mathrm{H}_{2} \mathrm{O}_{2} \\
(50 \mathrm{vol} .), \mathrm{HCl} \\
(1 \mathrm{M})+\mathrm{HF}(0.5 \mathrm{M}) \text { mixture } \\
\text { for } 100 \text { min at } \mathrm{RT}, 3-12 \mu \mathrm{m} \\
\text { grains selected by } \\
\text { sedimentation }\end{array}$ & $\begin{array}{l}\text { TL additive dose and } \\
\text { regeneration } \\
\text { technique. Alpha } \\
\text { efficiency by } \\
\text { comparison of TL } \\
\text { between beta and alpha } \\
\text { irradiated aliquots }\end{array}$ & $\begin{array}{l}\text { Annealing in air for } 1 \mathrm{~h} \text { at } \\
600,700,750 \text { and } 700^{\circ} \mathrm{C} \text {, } \\
\text { for samples } 1,2,8,10 \\
\text { respectively }\end{array}$ & $300-480{ }^{\circ} \mathrm{C}$ & $\begin{array}{l}\text { From } 2 \text { min to } 3 \text { months on } \\
\text { annealed material (beta } \\
\text { irradiation only) }\end{array}$ & $\begin{array}{l}\text { Preheat: } 120 \mathrm{~s} \text { at } 200^{\circ} \mathrm{C} \text {; } \\
4^{\circ} \mathrm{C} / \mathrm{s} \text {. Detect: } 2 \text {, Schott } \\
\text { BG12 and } 1 \text { IR rejection } \\
\text { MTO Ta3, PM EMI } \\
\text { 9813QKA; Lab designed } \\
\text { TL-reader }\end{array}$ \\
\hline CAT & $\begin{array}{l}\emptyset<40 \mu \mathrm{m} \text { sieving of gently } \\
\text { crushed material, } \mathrm{HCl}(1 \mathrm{M}) \\
\text { etching for } 100 \mathrm{~min} \text { at } \mathrm{RT} \text {, } \\
2-11 \mu \mathrm{m} \text { grain selection by } \\
\text { sedimentation }\end{array}$ & $\begin{array}{l}\text { TL additive dose and } \\
\text { low dose linearity } \\
\text { correction on annealed } \\
\text { material }\end{array}$ & $\begin{array}{l}\text { Annealed aliquots by two } \\
\text { "cut heat" at } 500{ }^{\circ} \mathrm{C} \text { while } \\
\text { TL measurements }\end{array}$ & $\begin{array}{l}310-360{ }^{\circ} \mathrm{C} \text { on } \\
\text { sample } 1 ; \\
350-400{ }^{\circ} \mathrm{C} \text { on } \\
\text { samples } 2,8,10\end{array}$ & $\begin{array}{l}\text { Check for fading after } 15 \\
\text { and } 30 \text { day storage (both } \\
\text { alpha and beta irradiated } \\
\text { aliquots) }\end{array}$ & $\begin{array}{l}\text { Preheat: } 120 \text { s at } 160,180 \text {, } \\
170,160^{\circ} \mathrm{C} \text { for samples } 1,2 \text {, } \\
8 \text { and } 10 ; 5^{\circ} \mathrm{C} / \mathrm{s} \text {. Detect: } \\
\text { Corning } 7-59 \text { and Schott } \\
\text { UG-11 and BG-39, PMT EMI } \\
\text { 9235QA; Risoe TL/OSL } \\
\text { reader }\end{array}$ \\
\hline MIL (TL) & $\begin{array}{l}30 \% \text { acetic acid etching } \\
(15 \text { min at } \mathrm{RT}), 2-11 \mu \mathrm{m} \\
\text { grain selection by } \\
\text { sedimentation }\end{array}$ & $\begin{array}{l}\text { TL additive dose and } \\
\text { low dose supralinearity } \\
\text { correction }\end{array}$ & $\begin{array}{l}\text { Annealed aliquots by two } \\
\text { "cut heat" at } 500{ }^{\circ} \mathrm{C} \text { while } \\
\text { TL measurements }\end{array}$ & $290-310{ }^{\circ} \mathrm{C}$ & $\begin{array}{l}\text { Check after } 6 \text { months } \\
\text { storage on beta irradiated } \\
\text { aliquots }\end{array}$ & $\begin{array}{l}\text { Preheat } 20 \text { s at } 200^{\circ} \mathrm{C} \text {; } \\
15^{\circ} \mathrm{C} / \mathrm{s} \text {. Detect: } 2 \text { Corning } \\
\text { BG12, PM EMI } 9635 \mathrm{QB} \text {; Lab } \\
\text { designed TL-reader }\end{array}$ \\
\hline
\end{tabular}


using TL dosimetry, the internal sample alpha and beta dose rates were determined by each laboratory according to the following procedures.

\subsubsection{Bordeaux}

The concentrations of Th, $\mathrm{U}$ and $\mathrm{K}$ were determined in samples using a high resolution, low background, gamma spectrometer employing a $15 \mathrm{~cm}$ thick lead shielded U-shape well Ge detector (Guibert et al., 2009). The radionuclide content of quartz grains used for luminescence measurements was also estimated using the well detector, although the sample size was inevitably limited $(<1 \mathrm{~g})$.

\subsubsection{Milan}

Alpha and beta dose rates were obtained by total alpha counting using ZnS scintillators screens ( $\mathrm{U}$ and $\mathrm{Th}$ ) and flame photometry (K).

\subsubsection{Catane}

ICP-MS measurements of bulk powdered samples and alpha counting were performed for determination of alpha and beta dose rates.

\subsubsection{Durham}

The beta dose rate (sources external to quartz grains) was determined directly using the technique of $\beta$-TLD (Bailiff, 1982), where each measurement was performed with $\sim 1 \mathrm{~cm}^{3}$ of ballmilled ceramic in an unsealed state. Typically up to 4 measurements with different fractions extracted from the powdered ceramic are performed. To assess the average internal grain dose rate, measurement of the average concentrations of parent $U$ and Th and $\mathrm{K}$ in quartz grains was performed using ICP-MS with handpicked quartz grains extracted from the crushed ceramic.

\section{Results}

Tables 3 and S2 contain internal radioactivity data of quartz grains, dose, dose rates and the final ages obtained.

\subsection{Coarse quartz grains}

\subsubsection{Bordeaux}

In calculating alpha and beta dose rates, annual dose conversion factors by Adamiec and Aitken (1998) were weighted by attenuation factors depending on grain size (Mejdahl, 1979; Brennan et al., 1991). A standard value of moisture content was applied ( $5 \pm 3 \%$, the water saturation percentage of bricks being close to $15 \%$ ). Significant concentrations of lithogenic radionuclides were found in the TL quartz grains analysed (Table 3). Although some samples

Table 3

Average concentrations of radionuclides (as parent) within quartz grains (i) used for TL measurements (Bordeaux) and (ii) hand-picked grains extracted from crushed ceramic (Durham).

\begin{tabular}{llll}
\hline Sample & $\mathrm{U}_{\text {internal }}(\mathrm{ppm})$ & $\mathrm{Th}_{\text {internal }}(\mathrm{ppm})$ & $K(\%)$ \\
\hline Bdx10222 & $<0.5$ & $1.11 \pm 0.83$ & $<0.05$ \\
Bdx10223 & $0.68 \pm 0.12$ & $0.84 \pm 0.36$ & $<0.05$ \\
Bdx10224 & $0.60 \pm 0.12$ & $0.67 \pm 0.38$ & $<0.05$ \\
Bdx10225 & $<0.5$ & $<1$ & $<0.1$ \\
Bdx10226 (STPG-8) & $0.64 \pm 0.22$ & $2.47 \pm 0.73$ & $<0.02$ \\
Bdx10227 & $0.27 \pm 0.07$ & $0.97 \pm 0.25$ & $<0.05$ \\
Bdx10229 & $0.35 \pm 0.16$ & $1.81 \pm 0.50$ & $<0.05$ \\
Bdx10230 & $0.35 \pm 0.17$ & $0.83 \pm 0.58$ & $<0.05$ \\
Mean \pm SD & $0.36 \pm 0.27$ & $1.09 \pm 0.75$ & - \\
Dur 321-1 (STPG-1) & $0.65 \pm 0.01$ & $1.25 \pm 0.02$ & 0.1 \\
\hline
\end{tabular}

The samples were measured using low background $\gamma$ spectrometry (Bdx) and using ICP-MS (Dur). could not be studied due to the lack of material, particularly the intercomparison samples 1,2 and 10 , we assigned to these unmeasured samples the $U$ and Th mean values calculated from the other bricks. Since the K content of quartz was below the detection limits, its contribution was neglected. The internal component in the annual alpha and beta doses of quartz (Table S2) was estimated assuming a uniform distribution of sources within the grains (alpha and beta), and the luminescence from zircons was neglected.

\subsubsection{Durham}

In the case of samples STPG-2, -8 and -10 , there was a significant change in the form of the decay curve following the measurement of the natural OSL (also accompanied by a significant slow decay component), and as a result of this alteration the quartz extracted was not considered suitable for reliable paleodose determination. For this reason, combined with the friability of the quartz grains in these samples as discussed above, the paleodose was determined only for sample STPG-1. Spatially resolved OSL measurement of aliquots of HF etched quartz (STPG-1) indicated that the majority of the OSL was emitted by a relatively small number of ultra bright grains. In calculating the annual dose, the $\beta$ dose rate derived from $\beta$ TLD measurements was corrected for attenuation using values calculated at Durham which are comparable with those published by Brennan (2003); the internal grain dose rate due to $\alpha$ and $\beta$ radiation was estimated assuming a uniform distribution of sources within the grains, an absence of luminescence from any zircon grains, and an alpha efficiency of $6 \%$. The assumed average moisture content was $3 \%$.

\subsection{Fine grains}

\subsubsection{Bordeaux, Catane and Milan}

Several marked differences in behaviour of the St Philbert fine grain samples were observed according to laboratory. Although the differences in TL curve shape may not be critical, they could be linked to the strikingly different observations of the degree of fading detected: its presence in the Bordeaux samples and its absence in the Milan and Catane samples. We tentatively conclude that this is mainly the result of differing mineralogical composition of the prepared fine grain fractions. The gentle $\mathrm{HF}(0.5 \mathrm{M})$ etching by Bordeaux aimed to clean grains of their baked clay coating to enhance their brightness (Guibert et al., 1998). Etching also removes unstable mineral species (for instance, amorphous material produced by firing), but, according to our experience, the feldspar minerals still remain. The preheat process and the optical window could play a secondary role in the fading observations (same filters used by BDX and MIL), in combination with the mineral composition. Another point is that the extent of the region of integration of the TL signals has no significant effect on TL loss, according to experiments by Bordeaux. In addition, differences in mineralogy after etching could cause noticeable differences in the alpha efficiency between laboratories. Finally, the fading observed by Bordeaux followed a logarithmic law of reduction that is characteristic of a tunnelling effect in feldspars (Visocekas, 1985; Zink, 1996) at a rate close to $3 \%$ per decade. The Bordeaux paleodose values for fine grain samples were corrected for anomalous fading.

\section{Age determinations}

As discussed above, the two arches from which the cores were sampled (STPG-1 and -2 from one and STPG- 8 and -10 from the other) were assessed on structural and stylistic grounds to be of the same (Carolingen) phase. If on the other hand there was 


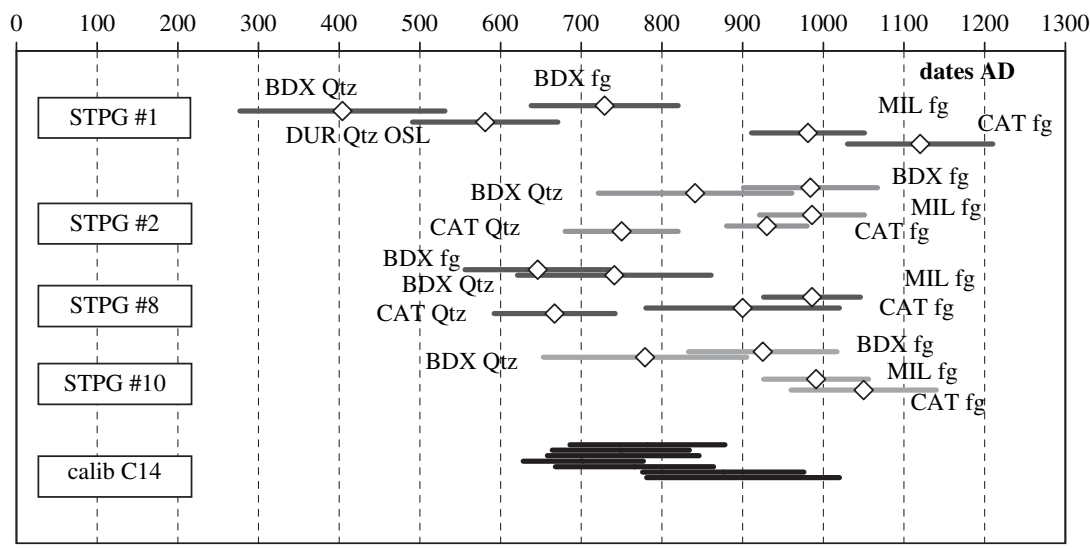

Fig. 3. Luminescence dating results of St Philbert bricks and comparison with radiocarbon data.

a chronological gap between the construction of the two arches, and the ceramics had been manufactured for their construction, we would expect coeval dates for each of the arches, but not necessarily an agreement between the two pairs STPG-1,2 and STPG-8,10. A third possible history of the bricks is that they were re-used Roman spolia, although this is considered unlikely on the basis of fabric type. Given the nature of the samples and the results, the simplest interpretation (single phase, Carolingen) is assumed at the outset of the discussion.

The calculated dates obtained by Bordeaux and Durham for coarse quartz grains (Table 5 and Fig. 3) extracted from STPG-1 agree within experimental error, although they appear to be older than the fine grain dates (BDX, MIL and CAT). Agreement of quartz TL ages of Bordeaux and Catane (STPG-2, -8 ) could be a coincidence since the technique used as a methodological test (SAR by Catane) provided inconsistent ages for samples 1 and 10 (2500 years and 2000 years respectively) that were obtained by their authors. In fact, the zeroing process of the method employed (Bassinet et al., 2006) does not account for significant sensitivity changes that may occur after the first heating at $500{ }^{\circ} \mathrm{C}$. The Bordeaux annealing experiments applied within their procedure suggests that the use of this procedure may give rise to an error in paleodose evaluation if not corrected (and therefore will need to be re-examined).

Comparison of fine grain dates between all laboratories without separating them according to their sample location, indicate that Catane and Milan results agree within quoted errors; the arithmetic averaged Milan/Catane date with standard deviation is $984 \pm 68 \mathrm{AD}$. The Bordeaux averaged fine grain date $(821 \pm 138 \mathrm{AD})$ differs significantly but is in better agreement with the quartz age $(670 \pm 130 \mathrm{AD})$. In addition, the fine grain ages for STPG- 1 and -8 by Bordeaux are significantly older than those obtained for STPG- 2 and $-10,\left(\chi^{2}=7.45\right.$ out of the $80 \%$ level of confidence range for 3 independent data [0.58-6.25]) indicating that the bricks were not manufactured during the same period of construction.

\section{Discussion}

The occurrence of radiogenically complex sample material, together with the issue of anomalous fading associated with the feldspar luminescence, can be expected to press the routine procedures to their limits, and in this respect the St Philbert samples have provided a challenging set of problems.

In terms of the dosimetry issues associated with the use of coarse quartz grains in a heterogeneous matrix, the presence of zircon as micro-inclusions may give rise to an underestimation of the annual dose, and in general the ages obtained with quartz are older than those for fine grains. Although the presence of radionuclide sources within the coarse quartz grains were taken into account in assessing the annual dose, this was on the basis of average determinations of radionuclide concentrations in small, but nonetheless 'bulk' samples. Using readily accessible techniques we were able to detect the presence of zircon crystals inside quartz grains with thin section analysis. Further investigation is now underway to test the distribution of paleodose obtained with single grains (OSL), which is expected to provide an indirect means of establishing whether the paleodose is affected by the presence of zircon micro-inclusions, rather due to the supplementary alpha irradiation of quartz by the radioactive inclusion than to zircon contribution to the OSL signal (Bailiff, submitted).

A further point related to coarse grain dosimetry is also of concern with the St Philbert bricks. Although measurements of radioactivity (e.g., gamma spectrometry) and dose rate have been performed with bulk or homogenised samples the beta dose rate within the sample is likely to be highly non-uniform. Evidence of heterogeneity in the $\beta$ dose rate in the study mentioned above (Bailiff, submitted) was detected in STPG-1 and a pivotal issue in future work will be the degree of paleodose averaging obtained (between individual grains contributing to the detected signal) for the aliquots of disaggregated grains used in this study.

Whether observed or not, the question of anomalous fading remains. We do not have an entirely satisfactory interpretation of the difference in behaviour observed between laboratories, although we believe each set of observations to be reliable. It is suspected that different etching procedures resulted in different mixtures of luminescent species in measurement samples. A concern for brick dating is whether the fine grain fraction is generally reliable in routine use. Although the fine grain technique can provide highly reproducible signals, the nature of the feldspar mixture contributing to the detected luminescence signal makes interpretation of fading behaviour problematic, particularly if experimental data do not match with any simple model. Over and above these considerations it is to be noted that the correction for fading applied by Bordeaux produced better agreement with the quartz ages and the mean fine grain age matches with the chronological interval given by radiocarbon data.

\section{Conclusion}

The question raised by this intercomparison study is the level of accuracy with which the age of the structures can be determined using one or more of the established techniques and further 
research will be focused on resolving this issue. This will include single grain analysis and spatially resolved investigation of radionuclide distribution and $\beta$ dose rate measurement.

\section{Acknowledgements}

This work was supported by the CNRS, within the framework of a European research network (GdRE) 'Architectural ceramics and dating methods', the Conseil Régional d'Aquitaine, the Universities of Bordeaux 3, Durham, Milano Bicocca, Catania and by a bilateral programme Alliance, a specific joint PhD grant by the Ministère de la Recherche et de l'Enseignement Supérieur. Special thanks to Christian Sapin (CNRS), Daniel Prigent (Conseil Général du Maineet-Loire), Armel Bouvier (PhD in progress at Univ. Bx3) and Scott Grainger (Luminescence Laboratory, Durham).

\section{References}

Adamiec, G., Aitken, M.J., 1998. Dose rate conversion factors: update. Ancient TL 16, 37-50.

Aitken, M.J., 1985. Thermoluminescence Dating. Academic Press, London, 359 pp.

Aitken, M.J., 1998. An Introduction to Optical Dating. The Dating of Quaternary Sediments by the Use of Photon Stimulated Luminescence. Oxford Science Publications, Oxford.

Bailiff, I.K., 1982. Beta-TLD apparatus for small samples. PACT 6, 72-76.

Bailiff, I.K., Holland, N., 2000. Dating bricks of the last two millennia from Newcastle upon Tyne: a preliminary study. Radiation Measurements 32, 615-619.

Bailiff, I.K., 2007. Methodological developments in the luminescence dating of brick from English late-medieval and post-medieval buildings. Archaeometry 49, $827-851$

Bailiff, I.K., submitted. Spatial variation of absorbed dose and $\beta$ dose rate in luminescence dating: identifying sources of variation in ceramic samples. Radiation Measurements (submitted).

Bassinet, C., Mercier, N., Miallier, D., Pilleyre, T., Sanzelle, S., Valladas, H., 2006. Thermoluminescence of heated quartz grains: intercomparisons between SAR an multiple aliquot additive dose techniques. Radiation Measurements 41, 803-808.

Blain, S., Guibert, P., Bouvier, A., Vieillevigne, E., Bechtel, F., Sapin, C., Baylé, M., 2007. TL dating applied to building archaeology: the case of the medieval church
Notre-Dame-Sous-Terre (Mont-Saint-Michel, France). Radiation Measurements 42, 1483-1491.

Brennan, B.J., Lyons, R.G., Phillips, S.W., 1991. Attenuation of alpha particle track dose for spherical grains. Radiation Measurements 18, 249-253.

Brennan, B.J., 2003. Beta dose rates to spherical grains. Radiation Measurements 37, 299-303.

Gallo, N., Fieni, L., Martini, M., Sibilia, E., 1999. Building archaeology, 14C and thermoluminescence: two examples comparison, in: Actes du Colloque C14 et Archéologie, III ${ }^{\circ}$ congrès international, Lyon, 6-10 April 1998. Mémoire de la Société Préhistorique Française, tome XXVI et Supplément de la Revue d'Archéométrie, 425-431.

Godfrey-Smith, D.I., Huntley, D.J., Chen, W.H., 1988. Optical dating studies of quartz and feldspar sediment extracts. Quaternary Science Reviews 7, 373-380.

Gueli, A.M., Marzo, F., Pedalino, A., Troja, S.O., 2001. TL dating of cuba of Saint Domenica (Castiglione di Sicilia). In: Guarino, A. (Ed.), Proceedings of 3rd International Congress on Science and Technology for the Safeguard of Cultural Heritage in the Mediterranean Basin II, pp. 876-880.

Guibert, P., Ney, C., Bechtel, F., Schvoerer, M., Araguas, Ph, 1998. Datation par thermoluminescence d'éléments architecturaux en terre cuite de la "Seo del Salvador", église cathédrale de Saragosse, Espagne. Revue d'Archéométrie 22, 125-135.

Guibert, P., Lahaye, C., Bechtel, F., 2009. The importance of U-series disequilibrium of sediments in luminescence dating: a case study at the Roc de Marsal cave (Dordogne, France). Radiation Measurements, 44, 223-231.

Lasteyrie, R., 1911. L'Eglise de Saint-Philbert-de-Grandlieu. Mémoires de l'Académie des Inscriptions et Belles Lettres XXXVIII, $2^{\mathrm{e}}$ partie.

Lebouteux, P., 1965. L'église Saint-Philbert de Grandlieu. Bulletin Archéologique du Comité des Travaux Historiques et Scientifiques. Nouvelle Série 1-2, 49-107.

Mejdahl, V., 1979. Thermoluminescence dating: beta-dose attenuation inquartz grains. Archaeometry 21, 61-72.

Mejdahl, V., 1985. Thermoluminescence dating of partially bleached sediments. Nuclear Tracks and Radiation Measurements 10, 711-715.

Roque, C., Guibert, P., Duttine, M., Vartanian, E., Chapoulie, R., Bechtel, F., 2004. Dependence of luminescence characteristics of irradiated quartz with thermal treatment and consequences for TL-dating: application to dating of Solutrean heated quartz pebbles from Laugerie Haute (Dordogne, France). Geochronometria 23, 1-8.

Visocekas, R., 1985. Tunnelling radiative recombination in labradorite: its association with anomalous fading of TL. Nuclear Tracks 10(4/6), 521-528.

Zink, A., 1996. Thermoluminescence des feldspaths: emission par effet tunnel et par thermoluminescence dans l'infra-rouge, incidences sur la datation des feldspaths, PhD thesis, University of Paris VII Denis Diderot and of Bordeaux III Michel de Montaigne, $275 \mathrm{pp}$. 